\title{
Endodontic treatment of a maxillary second premolar with three roots and three root canals - a case report
}

SADJ November 2019, Vol. 74 No. 10 p571 - p574

V Bookhan', GD Buchanan², ZI Vally³

\section{SUMMARY}

\section{Introduction}

There are currently no documented publications on an endodontic procedure performed on a maxillary second premolar with three roots and three root canals within a South African population.

This is a rare root canal configuration $(0.3 \%-2 \%)$, which, according to the endodontic literature, can be related to factors such as ethnicity, racial groups, and gender. Familiarity with root canal configurations within various ethnicities and racial groups is important in understanding the nature of the root canal system for successful endodontic procedures.

\section{Objectives}

The aim of this case report is to describe endodontics performed on a maxillary second premolar with three roots and three root canals, the patient being a South African female patient of African ethnicity. In addition, consideration is given to a suitable restorative option for the endodontically treated tooth.

The endodontic procedure is described in detail to inform dental practitioners. The diagnosis, location, instrumentation, and obturation of all the canals were successful. The location of the three canals required a large access cavity design that reduced the strength and support of the mineralized tissues. Therefore in this study, the preferred restoration for a maxillary second premolar with three roots and three root canals is a ceramic post crown.

Author affiliations:

1. Vinesh Bookhan: BDS, M Dent (Prosthodontics), Department of Odontology, School of Dentistry, University of Pretoria, South Africa.

ORCID Number: 0000-0002-4235-3897

2. Glynn D Buchanan: PG DIp Dent (Endodontics), MSc (Dentistry), Department of Odontology, School of Dentistry, University of Pretoria, South Africa.

ORCID Number: 0000-0003-2957-166X

3. Zunaid I Vally: BDS, MDent (Prosthodontics), Department of Odontology, School of Dentistry, University of Pretoria, South Africa.

ORCID Number: 0000-0001-7279-7547

Corresponding author: Vinesh Bookhan

Department of Odontology, School of Dentistry, University of Pretoria,

South Africa.

Email: vinesh.bookhan@up.ac.za

Author contributions:

1. Vinesh Bookhan: Main author $-50 \%$

2. Glynn D Buchanan: Co-author - $40 \%$

3. Zunaid I Vally: Co-author - $10 \%$

\section{Keywords}

Maxillary second premolar, three root canals, endodontic procedure, ceramic post crown

\section{INTRODUCTION}

Maxillary second premolars have a variety of root canal configurations. ${ }^{1,2}$ The most common configuration is one canal $(60 \%)$ followed by two canals $(40 \%) .{ }^{1}$ The maxillary second premolar with three root canals is rare $(0.3 \%-2 \%) .^{1-3,5,6}$ These configurations, according to the endodontic literature, can be related to factors such as ethnicity, racial groups, and gender..$^{1-3,5-13}$

It is very important to be familiar with root canal configurations which may be characteristic of various ethnic and racial groups because oral health practitioners who understand the nature of the complex root canal system can better locate and negotiate root canals and manage endodontic procedures successfully. . $^{4}$

The endodontic literature indicates that many countries have published articles on maxillary premolars within their population. ${ }^{1,4,14-20}$

Oral health practitioners are therefore able to familiarize themselves with the various root canal configurations that they may encounter when performing an endodontic procedure within their populations.

No documented publications have been found on endodontic procedures performed on maxillary second premolars with three roots and three root canals within a South African population.

Restoration of the endodontically treated tooth remains a challenge. ${ }^{21,22}$ A successful endodontic procedure requires a final restoration to restore the form, function, and aesthetics of the tooth and to improve the long term prognosis $^{23}$ An endodontically treated maxillary second premolar is susceptible to fracture because of cusp deflection. ${ }^{24}$ It is therefore essential that oral health practitioners choose a suitable restorative option for this tooth to improve the long term prognosis.

The aim of this case report is to describe an endodontic procedure performed on a maxillary second premolar with three roots and three root canals, in a South African female patient of African ethnicity. In addition, the report will consider a suitable restorative option for this tooth after completion of the endodontic procedure. 


\section{MATERIALS AND METHODS}

A South African female patient of African ethnicity was referred to the Division of Endodontics at the School of Dentistry for the completion of a root canal treatment on a maxillary second premolar with three roots and three root canals. An emergency root canal treatment had been previously performed in 2016 .

The tooth was asymptomatic at the initial consultation and had a temporary zinc-oxide eugenol restoration in place. Informed consent was obtained from the patient. A local anesthetic using 2 \% Lignocaine (Xylotox E80, Adcock Ingram, South Africa), was administered with 1:80 000 adrenaline content, using the infiltration technique both buccally and palatally.

The tooth was isolated with a nitrile rubber dam (Henry Schein, Gillingham, UK) and the entire procedure completed under a dental operating microscope (Global Surgical Corporation, St. Louis, MO). The temporary restoration was removed using a diamond-coated cylinder bur (Edenta, Hauptstrasse 7, Switzerland) in a fast handpiece.

The residual Ledermix paste (Lederle Pharmaceuticals, Wolfsratshausen, Germany) was rinsed out of the canals using a $3.5 \%$ sodium hypochlorite solution $(\mathrm{NaOCl}$, Jik, Reckitt Benckiser, South Africa).

The large oval access cavity design was completed using an Endo Z bur (Dentsply, Maillefer, Switzerland) to outline the walls and cavity floor of the pulp chamber.

Three distinct canal orifices were identified. The preoperative diagnostic radiograph demonstrated a palatal canal $(P)$, mesiobuccal (MB) canal and disto-buccal (DB) canal (Figure 1).

The following instrumentation procedures were performed:

- Working length determination using periapical radiographs and electronic apex locator (Propex Pixi, Dentsply Maillefer). The length of each canal was established and recorded on the patient's file (Figure 2). The canals were scouted and coronal flaring completed using a \#10 K-file.

- The glide path was prepared in all canals using a Proglider glide path file (Dentsply Maillefer, Ballaigues, Switzerland).

- The mesiobuccal and distobuccal canals were prepared using WaveOne Gold Primary reciprocating files (Dentsply Maillefer, Ballaigues, Switzerland).

- The palatal canal was initially prepared with a WaveOne Gold primary file and then further enlarged with a ProTaper Gold F3 and F4 file (Dentsply Maillefer, Ballaigues, Switzerland).

- Irrigation of the canals was performed using a 3,5\% $\mathrm{NaOCl}$ solution (Jik, South Africa) and a penultimate rinse of $17 \%$ EDTA liquid (Top clear EDTA) was used to remove the smear layer.

- Obturation (Figure 3) was completed using matching taper gutta-percha cones and BioRoot RCB Bioceramic sealer (Septodont, Saint Maur Des Fosses, France).
The single cone technique was used in the $\mathrm{MB}$ and DB canals and the conventional cold lateral condensation technique in the $P$ canal. The excess sealer was removed using ultrasonics and water.

- The orifices were sealed with a resin-modified glass ionomer (Vitrebond, 3M ESPE, St. Paul, MN) and a final bonded composite restoration (Filtek Supreme XTE, 3M ESPE, St. Paul, MN, Figure 4).

- The entire procedure was completed in a single session.

- The patient was referred to the restorative clinic for a ceramic crown supported by a fibre post and composite core restoration on the 25 and replacement of the DO restoration on the 24 which had been affected by recurrent caries.
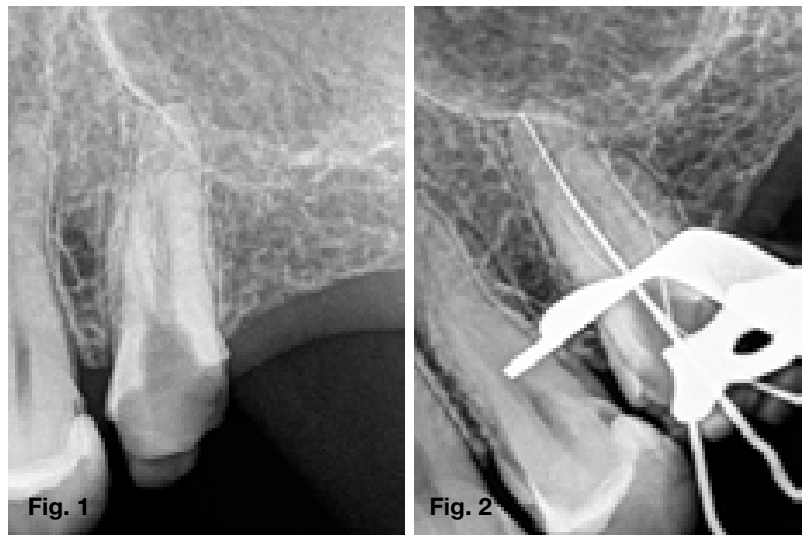

Figure 1. Pre-operative diagnostic radiograph.

Figure 2. Radiographic image of working length determination.
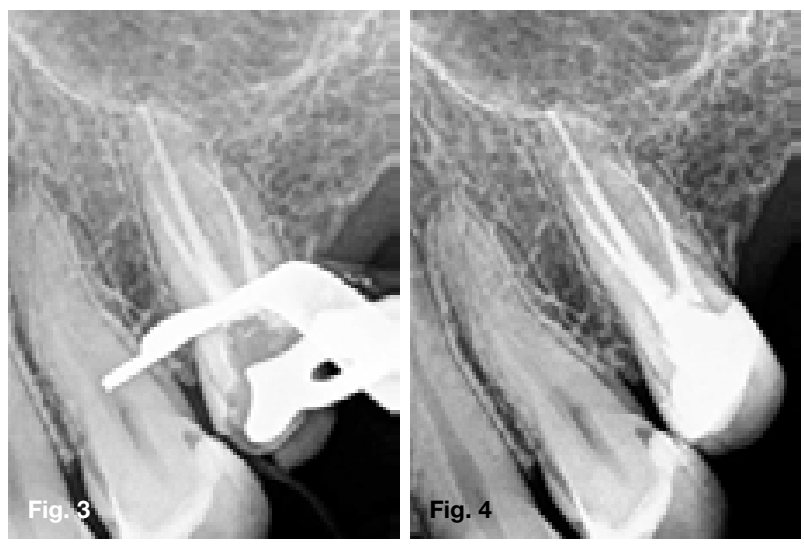

Figure 3. Radiographic image of obturation of 3 canals.

Figure 4. Radiographic image of completed endodontic treatment and composite restoration.

\section{RESULTS}

The diagnosis, location, instrumentation, and obturation of all three canals were successful.

\section{DISCUSSION}

Endodontic treatment of maxillary premolars remains a challenge because of the variety of root numbers and root canal configurations. ${ }^{1,2}$ It is important to identify all the root canals to ensure that the oral health practitioner can endodontically manage all the canals successfully. ${ }^{1,3-5,7}$ 
The location, negotiation, and obturation of each root canal require the accurate interpretation of radiographic images. ${ }^{1}$ During endodontic treatment, periapical radiographic images are frequently used for identifying the number of roots and root canals of teeth with a variety of configurations in order to make an accurate diagnosis. ${ }^{17,9,11,12}$

However these radiographs provide only a two-dimensional image and it may be necessary to take radiographic images from multiple angles to ensure that the additional canals within the three-dimensional root are not missed by the oral healthcare practitioner. . $^{1,7,9,15,12}$

Cone beam computed tomography (CBCT) is another accurate option for consideration as it allows a threedimensional view of teeth with complex root canal variations. ${ }^{21-24}$ In this case the diagnosis, location, negotiation, and obturation of the patient's maxillary second premolar was completed without the need for radiographic images from multiple angles since all the canals and roots were clearly visible on the initial radiographic image (Figure 1).

Magnification of the operating field using the dental operating microscope ensured improved visual acuity and favorable ergonomics for the oral health care practitioner resulting in an efficient and effective endodontic procedure. ${ }^{25}$

This variation of the maxillary second premolar with three roots and three root canals demonstrated morphology similar to the maxillary premolars described in the international endodontic literature..$^{1,4,14-20}$

Research involving the maxillary second premolar within a South African population is required to determine if other similarities or differences exist so that the results can be compared with the published research results of other countries.

The restoration of an endodontically treated premolar can be a challenge because the tooth is prone to fracture due to cusp deflection. ${ }^{26-28}$ It is therefore advisable to restore form and function with a reliable long term final restoration such as a bonded ceramic restoration that provides cuspal coverage. ${ }^{28,29}$

The success of the final restoration, however, depends on the structure of the remaining tooth. ${ }^{29,30}$ Accommodating straight-line access of three endodontic files into the openings of three root canal apertures frequently requires the destruction of a large part of the tooth crown. ${ }^{1,2}$

The ideal access cavity for a maxillary premolar with three canals is the classic "T shape" with two buccal canals (mesial and distal) and one palatal canal. ${ }^{2}$ However a more frequent design, due to caries destruction, is the oval-shaped access cavity and that may compromise the structure and strength of the mineralized tissues of the natural crown. ${ }^{2}$

This results in the natural tooth having insufficient support and strength to support the recommended ceramic restoration. Resistance and retention features to support the ceramic restoration must then be borrowed from the walls of the root canal space, applying adhesive techniques and the use of fibrereinforced composite posts. ${ }^{29,30}$

A ceramic restoration with cuspal coverage with or without the use of a fibre reinforced composite post is the preferred restoration..$^{29,31}$ The oral health care practitioner should, therefore, ensure that the root canal space selected to receive the post is instrumented to a sufficiently wide degree and to check that the root has sufficient length to accommodate a fibre-reinforced composite post.

This case report suggests that the palatal root canal space of a second maxillary premolar is the preferred root canal space to receive a fibre-reinforced composite post. The following factors must, therefore, be taken into consideration before entering the restorative phase of a maxillary second premolar:

1. Affordability (can the patient afford to pay for the ceramic crown),

2. Design of the retention space (can the root and root canal space support a post and core).

3. The health of the periodontium (is the periodontal status and oral hygiene favourable).

4. The abutment design (can the abutment incorporate a ferrule design to support a post and core).

If the answer to any of the above factors is a "no", then an alternative treatment plan, suitable for the particular patient, should be considered.

\section{CONCLUSION}

Anatomical variations of premolars have a direct effect on the diagnosis, treatment plan and prognosis of endodontic treatment. ${ }^{32}$ This case report is intended to help oral health care practitioners improve their awareness of the procedural and restorative challenges that they may face when performing endodontic treatment on a maxillary second premolar with three roots and three canals.

The location of all three canals required a large access cavity design that reduced the strength and support of the mineralized tissues. The suggested long term restoration for such a maxillary second premolar is a bonded ceramic restoration that provides cuspal coverage with a fibre reinforced composite post.

\section{Patient consent}

The authors certify that consent for the procedure performed on the patient was obtained. A waiver of informed consent for the publication of this case study was obtained from the Research Ethics Committee.

The patient's identity was not disclosed.

\section{Conflict of interest}

No conflict of interest is declared by the authors. 


\section{References}

1. Nazeer MR, Khan FR, Ghafoor R. Evaluation of root canal morphology and canal configuration of maxillary premolars in a sample of Pakistani population by using cone beam computed tomography. J Pak Med Assoc. 2018; 68(30): 423-7.

2. Golmohammadi $M$, Jafarzadeh $H$. Root canal treatment of a maxillary second premolar with two palatal root canals: A case report. Iran Endod J. 2016; 11(3): 234-6.

3. Mohammadi Z, Shalavi S, Giardino L, Asgary S. Endodontic considerations in three-canalled premolars: A practical update. Iran Endod J. 2016; 11(2): 134-7.

4. Banga Singh K, Pawar AM, Nagpal D, Lange J, Thakur B, Rastogi S. Root canal morphology of premolar teeth in the population of Maharashtra (Pune) compared to the other Indian populations. Endodontics 2018; 30(1): 15-20.

5. Reddy PM, Malu KNM, Kumar P, Patil SS, Sawagave SS. Endodontic management of maxillary second premolar with three canals: A case report. Int J Contemp Dent. 2011; 2(5): 19-21.

6. Kothandaraman S, Manali RS, Sundaresan B, Lingeswaran P. Report of occurrence and endodontic management of three-rooted maxillary first and second premolars in the same individual. Indian J Dent Res. 2017; 28(3): 337-40.

7. Yeh C-S, Wong W-B, Kan W Y-W, Tu M-G. Root canal treatment of a three-rooted maxillary second premolar. J Dent Sci. 2017; 12(1): 95-7.

8. Izaz S, Mandava P, Bolla N, Bhargavi D. Atypical anatomy of maxillary second premolar with three roots and four canals. J Conserv Dent. 2017; 20(5): 370-3.

9. Gingu KG, Anju MV \& Aravindan D. Root canal treatment of a maxillary second premolar with two palatal roots: A case report. J Conserv Dent. 2014; 17(3): 290-2.

10. Chauhan R, Singh S. Endodontic management of threerooted maxillary second premolar in a patient with the bilateral occurrence of three roots in maxillary second premolars. J Clin Exp Dent. 2012; 4(5): 317-20.

11. Barros DB, Tanomaru JMG, Filho T. Root canal treatment of three-rooted maxillary second premolars: Report of four cases. Aust Endod J. 2009; 35: 73-7.

12. Arisu HD \& Alacam T. Diagnosis and treatment of threerooted maxillary premolars. Eur J Dent. 2009; 3: 62-6.

13. De Almeida-Gomes F, de Sousa BC, de Souza FD, dos Satos RA, Ferreira CM. Unusual anatomy of maxillary second premolars. Eur J Dent. 2009; 3: 145-9.

14. Saber SEDM, Ahmed MHM, Obeid M, Ahmed HMA. Root and canal morphology of maxillary premolar teeth in an Egyptian subpopulation using two classification systems: a cone beam computed tomography study. Int Endod J. 2018; 52(3): 267-78.

15. Bürklein S, Heck R, Schäfer $E$. Evaluation of root canal anatomy of maxillary and mandibular premolars in a selected German population using cone-beam computed tomographic data. J Endod. 2017; 43(9): 1448-52.

16. Lin $Y$, Chen $X$, Cheng $T$, Ting $H$, Yan W. Use of cone beam computed tomography to evaluate root canal morphology and locate root canal orifices of maxillary second premolars in a Chinese subpopulation. J Endod. 2014; 40(5): 630-4.

17. Evren OK, Altunsoy M, Nur BG, Aglarci OS, Colak M, Gungor E. A cone-beam computed tomography study of root canal morphology of maxillary and mandibular premolars in a Turkish population. Acta Odontologica Scandinavica 2014; 72: 701-6.

18. Oginni A. Clinical radiographic estimation of the number of root canals in maxillary first and second premolars among Nigerians. Internet J Dent Sci. 2004; 2(1): 1-6.

19. Abella F, Teixido LM, Patel S, Sosa F, Duran-Sindreu, Roig M. Cone-beam computed tomography analysis of the root canal morphology of maxillary first and second premolars in a Spanish population. J Endod. 2015; 41(8): 1241-7.
20. Elnour M, Khabeer A, Al Shwaimi E. Evaluation of root canal morphology of maxillary second premolars in a Saudi Arabian sub-population: An in vitro microcomputed tomography study. Saudi Dent J. 2016; 28: 162-8.

21. Alqedairi A, Alfawaz H, Al-Dahman, Al-Nassar F, Al-Jebaly A, Alsubait $\mathrm{S}$. Cone beam computed tomographic evaluation of root canal morphology of maxillary premolars in a Saudi population. BioMed Res Int. 2018; 4: 1-8.

22. Reuben J, Velmurugan N, Vasanthi S, Priya, Vijayalakshmi. Endodontic management of a maxillary second premolar with an S-shaped root canal. J Conserv Dent. 2008; 11(4): 168-70.

23. Ferreira CM, de Moraes IG, Bernardineli N. Three-rooted maxillary second premolar. J Endod. 2000; 26(2): 105-6.

24. Kartal N, Özçelik B, Cimilli $H$. Root canal morphology of maxillary premolars. J Endod 1998; 24(6): 417-9.

25. Low JF, Dom TNM, Bahrain SA. Magnification in endodontics: a review of its application and acceptance among dental practitioners. Eur J Dent. 2018; 12(4): 610-6.

26. Karzoun W, Abdulkarim A, Samran A, Kern M. Fracture strength of endodontically treated maxillary premolars supported by a horizontal glass fibre post: an in vitro study $J$ Endod. 2015; 41(6): 907-12.

27. Moezizadeh M, Mokhtari N. Fracture resistance of endodontically treated premolars with direct composite restorations. J Conserv Dent. 2011; 14(3): 277-81.

28. Seouw LL, Toh CG, Wilson NHF. Strain measurements and fracture resistance of endodontically treated premolars restored with all-ceramic restorations. J Dent. 2015; 43: 126-32.

29. Mannocci F, Cowie J. Restoration of endodontically treated teeth. Br Dent J. 2014; 216(6): 341-6.

30. Scotti N, Rota R, Scansetti M, et al. Influence of adhesive techniques on fracture resistance of endodontically treated premolars with various residual wall thicknesses. J Prosthet Dent. 2013; 110: 376-82.

31. Zarow M, Ramirez-Sebastian, Gaetano P et al. A new classification system for the restoration of root filled teeth. Int Endod J. 2018; 51: 318-34.

32. Ugur Z, Akpinar KE, Altunbas D. Maxillary first premolars with three root canals: Two case reports. J Istanbul Univ Fac Dent. 2017; 51(3): 50-4. 